\title{
Increased UCP1 expression in the perirenal adipose tissue of patients with renal cell carcinoma
}

\author{
XUEQIN LI ${ }^{1 *}$, GONGCHENG WANG $^{2 *}$, JUAN LIU $^{3}$ and GUOXIAN DING ${ }^{3}$ \\ Departments of ${ }^{1}$ Gerontology and ${ }^{2}$ Urology, The Affiliated Huai'an No. 1 People's Hospital of \\ Nanjing Medical University, Huai'an, Jiangsu 223300; ${ }^{3}$ Department of Geriatric Endocrinology, \\ The First Hospital Affiliated to Nanjing Medical University, Nanjing, Jiangsu 210029, P.R. China
}

Received March 7, 2019; Accepted August 7, 2019

DOI: $10.3892 /$ or.2019.7306

\begin{abstract}
Perirenal adipose tissue (PAT) has been implicated in renal cell carcinoma (RCC). The expression of uncoupling protein 1 (UCP1) is higher in PAT compared with that in back subcutaneous adipose tissue (bSAT). The aim of the present study was to determine UCP1 expression in different parts of PAT and to analyze the correlation between UCP1 expression in PAT and RCC. PAT from the upper and lower renal poles and bSAT samples were collected from 50 patients with RCC (RCC group) and 54 patients with renal cysts (control group) who had undergone renal surgery. Both UCP1 mRNA and protein levels were found to be significantly higher and adipocytes appeared to be smaller in the PAT of the RCC group. Furthermore, the RCC group had more multilocular UCP1-positive adipocytes. UCP1 staining in the PAT was significantly stronger in the RCC group, but there was no significant difference in UCP1 staining in the bSAT between the two groups. Furthermore, Fuhrman grade and T stage were higher in the high UCP1 expression group of RCC patients. In conclusion, high UCP1 expression in the PAT may serve as an indicator of poor prognosis in RCC.
\end{abstract}

\section{Introduction}

Renal cell carcinoma (RCC) is a common type of kidney cancer in adults $(1,2)$. The incidence of RCC is increasing and 270,000 cases are diagnosed on an annual basis worldwide (3). Important risk factors for RCC include obesity, hypertension, smoking and advanced kidney disease $(4,5)$.

Correspondence to: Dr Juan Liu, Department of Geriatric Endocrinology, The First Hospital Affiliated to Nanjing Medical University, 300 Guangzhou Road, Nanjing, Jiangsu 210029, P.R. China

E-mail: lioujane@njmu.edu.cn

*Contributed equally

Key words: uncoupling protein 1, perirenal adipose tissue, brown adipose tissue, renal cell carcinoma
In particular, a body mass index $(\mathrm{BMI})>25 \mathrm{~kg} / \mathrm{m}^{2}$ has been found to be significantly correlated with an increased risk of $\operatorname{RCC}(6,7)$.

Apart from insulin signaling and insulin-like growth factor, adipocytokines released from adipose tissue may represent a link between obesity and RCC (8-10). The inflammatory marker tumor necrosis factor (TNF)- $\alpha$ is upregulated in RCC patients and may promote $\operatorname{RCC}(11,12)$. Human perirenal adipose tissue (PAT) is located in the retroperitoneum and protects the kidneys and renal arteries from external mechanical forces. Lamacchia et al (13) found that the thickness of PAT may predict chronic kidney disease and hyperuricemia in patients with diabetes. Furthermore, tumor invasion in the PAT is an indicator of poor prognosis $(14,15)$. However, the role of PAT in RCC remains unclear.

Adipose tissue includes brown adipose tissue (BAT) and white adipose tissue (WAT). While WAT serves as energy storage, BAT dissipates the energy as heat. Uncoupling protein 1 (UCP1) is a protein specifically expressed in BAT to promote the uncoupling of the respiratory chain and the conversion of energy to heat (16). BAT has been reported to be involved in several human diseases, such as cancer-associated cachexia (17-21). A previous study reported that PAT is a brown fat-like deposit, and UCP1 expression in the PAT of hypertensive patients is lower compared with that in controls (22). However, to the best of our knowledge, the association between UCP1 expression in PAT and RCC has not been reported to date. The aim of the present study was to determine UCP1 expression in different parts of the PAT, and to analyze the association between UCP1 expression in the PAT and RCC.

\section{Patients and methods}

Patients. A total of $50 \mathrm{RCC}$ patients and 54 patients with renal cyst undergoing retroperitoneal laparoscopic surgery were recruited in the present study. Patients with chronic kidney disease, musculoskeletal diseases, inflammatory or autoimmune diseases and adrenal or other tumors were excluded from the study. All RCC cases were confirmed as clear cell carcinoma by postoperative pathological diagnosis. All renal cyst cases were simple cysts, without infection or hemorrhage. Moreover, renal cysts, unlike tumors, do not secrete any cytokines that may affect PAT and bSAT. Therefore, renal cyst cases were used as 
the control group. The patients in both the RCC and control groups were matched for age and BMI. PAT samples were collected between February 2013 and October 2013, in order to avoid the effect of winter on UCP1 expression in adipose tissue. All the subjects stayed in the patients' ward, under a controlled temperature at $\sim 20-25^{\circ} \mathrm{C}$ for $3-4$ days prior to surgery. When undergoing elective surgery, the temperature of the operating theater was also controlled at $20-25^{\circ} \mathrm{C}$. PAT was analyzed by dividing it into two different parts: Upper and lower renal pole PAT. The different sources of PAT were removed using a standard endoscopic retroperitoneal approach and bSAT was removed using a scalpel; both were kept at $-80^{\circ} \mathrm{C}$. The Ethical Board of Nanjing Medical University approved the study protocols and all subjects provided written informed consent.

Clinical data, including age, gender, history of hypertension and diabetes, smoking status, body mass index (BMI), waist circumference (WC), basal body temperature (BBT), systolic and diastolic blood pressure (SBP and DBP, respectively) and resting heart rate (RHR), were collected from medical records. Fasting blood samples were collected, and then the plasma levels of glucose, creatinine $(\mathrm{Cr})$, triglyceride $(\mathrm{TG})$, low-density lipoprotein cholesterol (LDL-C), high-density lipoprotein cholesterol (HDL-C), total cholesterol (TC), as well as the creatinine clearance rate $(\mathrm{CCr})$, were measured on a Hitachi 7600 automatic analyzer (Boehringer Mannheim).

Reverse transcription-quantitative polymerase chain reaction (RT-qPCR) analysis. Total RNA was isolated from tissues using TRIzol (Life Technologies; Thermo Fisher Scientific, Inc.). Total RNA $(2 \mu \mathrm{g})$ was reverse-transcribed with $200 \mathrm{U}$ M-MLV RT (Promega Corporation), in the presence of $0.5 \mathrm{mmol} / 1$ deoxynucleotide triphosphate, $25 \mathrm{U}$ RNase inhibitor and $0.5 \mathrm{mg}$ N15 random primers, in a total volume of $25 \mu \mathrm{l}$. The primers were designed by Primer 5 software (Premier, Inc.) and are listed in supplementary Table SI. PCR was performed in triplicate using a SYBR Green PCR Master kit (Toyobo Life Sciences) in a $25-\mu 1$ volume. The PCR program was designed as follows: $60 \mathrm{sec}$ at $95^{\circ} \mathrm{C}$, followed by 40 cycles of $15 \mathrm{sec}$ at $95^{\circ} \mathrm{C}, 15 \mathrm{sec}$ at $60^{\circ} \mathrm{C}, 45 \mathrm{sec}$ at $72^{\circ} \mathrm{C}$, and $5 \mathrm{sec}$ at $80^{\circ} \mathrm{C}$ on a plate reader (Rotor Gene-3000; Corbett Research). Expression levels were calculated based on the $2^{-\Delta \Delta \mathrm{Cq}}$ method (23).

Western blot analysis. Tissues were incubated in RIPA buffer, and equal amounts of lysates were separated by $10 \%$ SDS-PAGE and transferred to a polyvinylidene difluoride membrane (EMD Millipore). The membranes were incubated with primary antibodies against UCP1 (rabbit polyclonal, 1:1,000; Abcam; ab10983) or tubulin (rabbit polyclonal, 1:5,000; Abcam; ab59680) at $4^{\circ} \mathrm{C}$ for $12 \mathrm{~h}$, and sequentially incubated with secondary antibodies (sheep anti-rabbit polyclonal IgG labeled with horseradish peroxidase, 1:20,000; Abcam; ab6795) at room temperature for $2 \mathrm{~h}$. Protein levels were quantified using Quantity One software (Bio-Rad Laboratories, Inc.).

Immunohistochemical analysis. Tissues were fixed in 10\% formalin, embedded in paraffin, cut into 5- $\mu \mathrm{m}$ sections and stained with hematoxylin and eosin for morphological observation. The sections were then incubated with UCP1 antibody (rabbit polyclonal, 1:500; Abcam; ab10983) for $30 \mathrm{~min}$, and then with secondary antibody for UCP1 staining (sheep anti-rabbit polyclonal IgG labeled with horseradish peroxidase, 1:800; Abcam; ab6795). The staining results were analyzed using CellSense Dimension software (Olympus Corporation).

Statistical analysis. Data were analyzed using SPSS v20.0 software (IBM Corp.). Continuous variables were analyzed by t-test, and categorical variables were analyzed by $\chi^{2}$ test. Spearman's correlation analyzed the association between the variables and linear regression analysis assessed the strength of the association. $\mathrm{P}<0.05$ (two-tailed) was considered to indicate a statistically significant difference.

\section{Results}

Expression levels of UCP1 in different parts of PAT. PAT was divided into two parts, namely upper and lower renal pole PAT, and it was observed that the adipocytes in the two different sources of PAT were similar (Fig. 1A and B), as were the cell numbers (Fig. 1C). Moreover, there was no difference in UCP1 staining between the two sources (Fig. 1D and E). Furthermore, there were no differences in UCP1 mRNA and protein levels between the two sources (Fig. 1F-H). In addition, the expression of BAT genes, WAT genes, proinflammatory cytokines, adipocytokines and mitochondrial genes were compared between the two different sources of PAT, and no significant differences were observed (Fig. 1H-M).

The expression levels of UCP1 are higher in PAT from RCC. Next, the expression of UCP1 in bSAT samples from the RCC and control groups was examined, and no significant differences in UCP1 mRNA expression (Fig. 2A) and other mRNA expression (Fig. 2A-F) were observed. In addition, the adipocytes were smaller in the PAT of the RCC group compared with that of the control group (Fig. 3A and B) and their number was significantly higher compared with the control group (Fig. 3C). Furthermore, multilocular adipocytes were significantly smaller and UCP1 staining was stronger in the PAT from the RCC group (Fig. 3D and E), whereas both the mRNA and protein levels of UCP1 were higher in the RCC group compared with those in the control group (Fig. 3F-H).

Comparison of PAT gene expression between the control and $R C C$ groups. To analyze the associations between increased expression of UCP1 and that of other BAT genes in PAT from the RCC group compared with the control group, other BAT genes were examined and no significant differences were identified between the two groups (Fig. $3 \mathrm{H}$ ).

In addition, no significant difference was found in TBX1, TMEM26 or CD137 expression in PAT samples between the two groups (Fig. 3I). However, the mRNA levels of HOXC8 and HOXC9 were lower in the RCC group compared with those in the control group (Fig. 3J).

Furthermore, the expression of cytochrome $c$ oxidase subunit VIIa polypeptide 1, cytochrome $c$-1, citrate synthase, long-chain acyl-CoA dehydrogenase caldesmon and pyruvate dehydrogenase kinase isozyme 4 in PAT samples did not differ significantly between the two groups (Fig. 3K). The expression of the adipocytokines ADIPQ and LEP also exhibited no significant difference between the two groups (Fig. 3L). Moreover, the expression of the inflammatory 

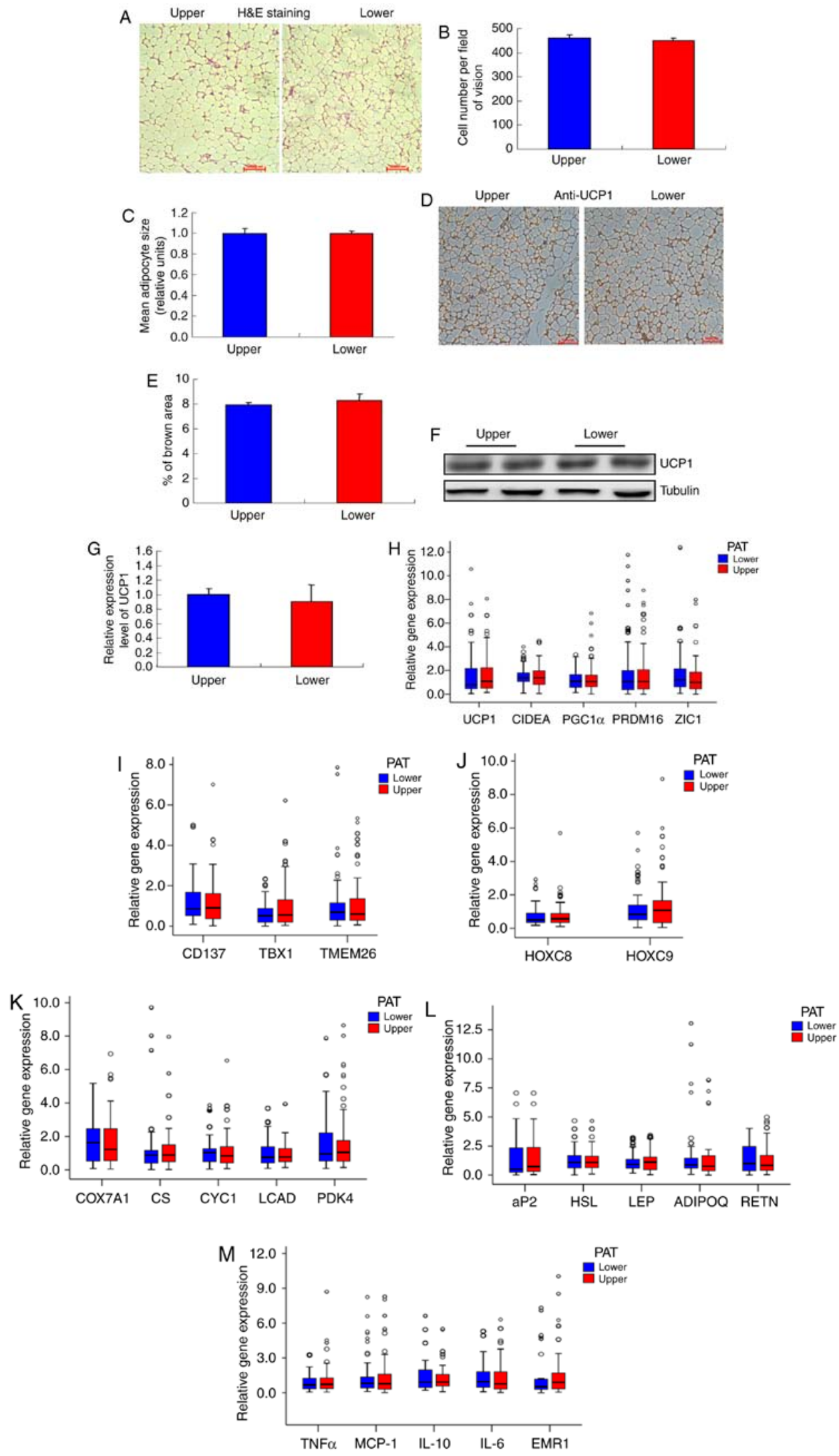

Figure 1. Characterization of different parts of the PAT. (A) Morphology of the upper and lower renal poles. Representative hematoxylin and eosin (H\&E) staining images are shown $(n=20)$. (B) Size of adipocytes in the upper and lower renal pole fat pads (magnification, $x 200)$. Data represent the mean \pm standard deviation (SD), $n=20$. (C) Number of adipocytes in the upper and lower renal pole fat pads (magnification, $x 200$ ). Data represent the mean $\pm S D, n=20$. (D) UCP1 staining in the upper and lower renal poles. Representative images are shown $(n=20)$. (E) Quantification of UCP1 staining in the upper and lower renal poles. Data represent the mean $\pm \mathrm{SD}, \mathrm{n}=10$. ( $\mathrm{F}$ and G) Western blot analysis of the UCP1 level in the upper and lower renal poles $(\mathrm{n}=6)$. (H) RT-qPCR analysis of the mRNA levels of UCP1 and other BAT genes in the upper and lower renal poles (n=104). (I and J) RT-qPCR analysis of the mRNA levels of white adipocyte and brown adipocyte genes in the upper and lower renal poles $(\mathrm{n}=104)$. (K-M) RT-qPCR analysis of the mRNA levels of metabolism-related genes and mitochondrial genes in the upper and lower renal poles $(\mathrm{n}=104)$. PAT, perirenal adipose tissue; RT-qPCR, reverse transcription-quantitative polymerase chain reaction; UCP1, uncoupling protein 1; BAT, brown adipose tissue. 

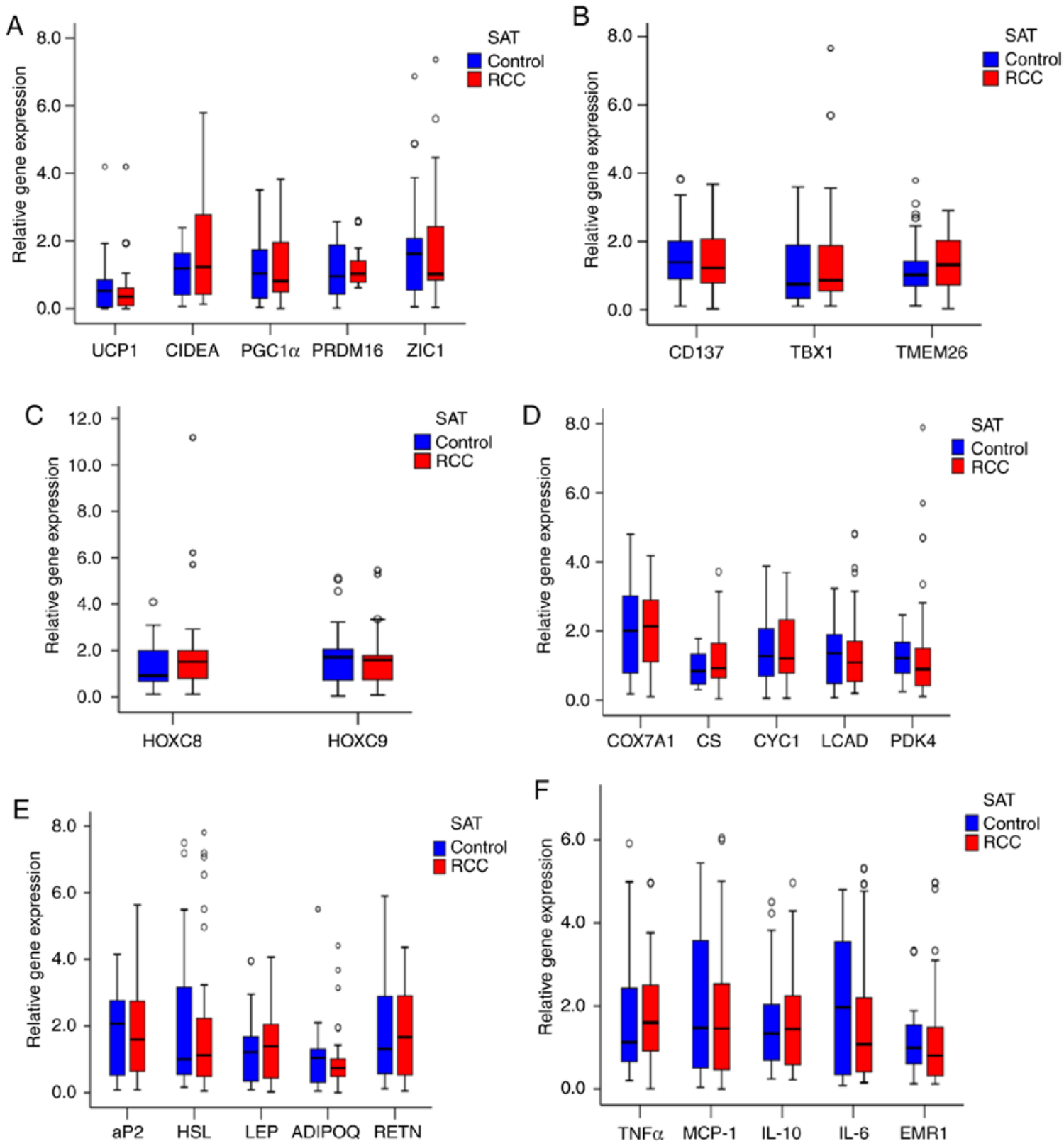

Figure 2. Expression of UCP1 and other genes in the bSAT of the RCC and control groups. (A) RT-qPCR analysis of UCP1 and other BAT genes in bSAT $(n=104)$. (B) RT-qPCR analysis of brown adipocyte genes in the RCC and control groups $(n=104)$. (C) RT-qPCR analysis of white adipocyte genes in the RCC and control groups (n=104). (D-F) RT-qPCR analysis of the mRNA levels of metabolism-related genes and mitochondrial genes in the RCC and control groups $(\mathrm{n}=104)$. RCC, renal cell carcinoma; RT-qPCR, reverse transcription-quantitative polymerase chain reaction; UCP1, uncoupling protein 1; BAT, brown adipose tissue; bSAT, back subcutaneous adipose tissue.

factors monocyte chemotactic protein-1 and TNF- $\alpha$ was not significantly different between the two groups (Fig. 3M).

Comparison of baseline characteristics between the control and RCC groups. The activation of BAT is affected by several factors, such as sex, age, BMI and fasting blood glucose (24-26). To validate whether the increased UCP1 expression in the PAT of the RCC group was associated with clinical factors, clinical data from the two groups were analyzed; no significant differences were identified (Table I).

Comparison of baseline characteristics of RCC between the high and low UCP1 expression groups. Several aspects of RCC, such as Fuhrman grade, T stage, histopathology and necrosis, are involved in RCC tumorigenesis. The higher the Fuhrman grade and $\mathrm{T}$ stage, the worse the tumor progression and patient prognosis. To determine the association between UCP1 expression in the PAT and progression of RCC, Spearman's correlation coefficients of UCP1 mRNA expression with Fuhrman grade and T stage of RCC were assessed using SPSS v20.0 software. The expression of UCP1 mRNA was found to be significantly positively correlated with Fuhrman grade and T stage in RCC (Figs. 4 and 5). The clinical characteristics of RCC patients with high UCP1 expression were compared with those in patients with low UCP1 expression, as defined using the median method. The median cut-off point of UCP1 mRNA expression was 1.663; according to this, the 50 RCC patients were divided 



Figure 3. Higher UCP1 expression in the PAT of the RCC group. (A) Morphology of the PAT. Representative hematoxylin and eosin (H\&E) staining images are shown $(\mathrm{n}=20)$. (B) Size of adipocytes in the RCC and control groups (magnification, $\mathrm{x} 200)$. Data are presented as the mean \pm standard deviation $(\mathrm{SD})$, $\mathrm{n}=20\left({ }^{* * *} \mathrm{P}<0.001\right)$. (C) Number of adipocytes in the RCC and control groups (magnification, $\left.x 200\right)$. Data are presented as the mean $\pm S D, n=20$. $\left({ }^{* * *} P<0.001\right)$. (D) UCP1 staining in the PAT of the RCC and control groups. Representative images are shown ( $\mathrm{n}=20)$. (E) Quantification of UCP1 staining in the RCC and control groups. Data are presented as the mean $\pm \mathrm{SD}, \mathrm{n}=10\left({ }^{* * * *} \mathrm{P}<0.001\right)$. ( $\mathrm{F}$ and $\left.\mathrm{G}\right)$ Western blot analysis of the UCP1 level in the PAT of the RCC and control groups $(\mathrm{n}=8)\left({ }^{* * *} \mathrm{P}<0.001\right)$. (H) RT-qPCR analysis of the mRNA levels of UCP1 and other BAT genes in the RCC and control groups $\left({ }^{* *} \mathrm{P}<0.01\right)(\mathrm{n}=104)$. (I and J) RT-qPCR analysis of the mRNA levels of white adipocyte and brown adipocyte genes in the PAT of the RCC and control groups ( $\mathrm{n}=104)$ ( $\mathrm{P}<0.05$, $\left.{ }^{* * * *} \mathrm{P}<0.001\right)$. (K-M) RT-qPCR analysis of the mRNA levels of adipocyte metabolism-related genes and mitochondrial function genes in the PAT of the RCC and control groups ( $\mathrm{n}=104)$. PAT, perirenal adipose tissue; RCC, renal cell carcinoma; RT-qPCR, reverse transcription-quantitative PCR; UCP1, uncoupling protein 1. 
Table I. Description and comparison of clinical and biochemical characteristics of the study patients.

\begin{tabular}{|c|c|c|c|}
\hline Characteristics & Control group $(n=54)$ & RCC group $(n=50)$ & P-value \\
\hline Age (years) & $50.35 \pm 10.48$ & $52.18 \pm 8.31$ & 0.329 \\
\hline Male sex, n (\%) & $27(50.00)$ & $25(50.00)$ & 1.000 \\
\hline BMI $\left(\mathrm{kg} / \mathrm{m}^{2}\right)$ & $24.49 \pm 3.29$ & $24.30 \pm 2.93$ & 0.766 \\
\hline $\mathrm{WC}(\mathrm{cm})$ & $88.94 \pm 9.15$ & $90.08 \pm 11.08$ & 0.569 \\
\hline Smoking, n (\%) & $10(18.52)$ & $12(24.00)$ & 0.494 \\
\hline Hypertension, n (\%) & $13(24.07)$ & $15(30.00)$ & 0.496 \\
\hline Diabetes, n (\%) & $3(5.56)$ & $4(8.00)$ & 0.916 \\
\hline $\operatorname{BBT}\left({ }^{\circ} \mathrm{C}\right)$ & $36.44 \pm 0.31$ & $36.48 \pm 0.27$ & 0.538 \\
\hline $\mathrm{SBP}(\mathrm{mmHg})$ & $121.59 \pm 13.18$ & $123.90 \pm 17.32$ & 0.449 \\
\hline $\mathrm{DBP}(\mathrm{mmHg})$ & $76.56 \pm 7.56$ & $75.68 \pm 11.11$ & 0.642 \\
\hline RHR (bpm) & $72.98 \pm 7.34$ & $74.26 \pm 6.86$ & 0.362 \\
\hline FBG (mmol/l) & $5.62 \pm 1.06$ & $5.32 \pm 0.98$ & 0.147 \\
\hline $\mathrm{TG}(\mathrm{mmol} / \mathrm{l})$ & $1.34 \pm 0.43$ & $1.34 \pm 0.50$ & 0.946 \\
\hline $\mathrm{TC}(\mathrm{mmol} / \mathrm{l})$ & $4.44 \pm 0.80$ & $4.53 \pm 0.83$ & 0.591 \\
\hline LDL-C (mmol/l) & $2.91 \pm 0.47$ & $2.89 \pm 0.47$ & 0.796 \\
\hline HDL-C (mmol/l) & $1.24 \pm 0.24$ & $1.31 \pm 0.28$ & 0.194 \\
\hline $\mathrm{Cr}(\mu \mathrm{mol} / \mathrm{l})$ & $71.15 \pm 14.03$ & $73.68 \pm 23.46$ & 0.510 \\
\hline $\mathrm{CCr}$ & $90.93 \pm 17.09$ & $84.98 \pm 20.17$ & 0.106 \\
\hline$\beta$-blockers, n (\%) & $1(1.85)$ & $2(4.00)$ & 0.946 \\
\hline
\end{tabular}

Data were analyzed by unpaired t-tests. All values are expressed as mean \pm standard deviation for continuous variables and as number of patients (percentage) for categorical variables. Continuous variables were analyzed by independent-sample t-tests; two-sided type I error of 0.05 . Categorical variables were analyzed by $\chi^{2}$ tests. RCC, renal cell carcinoma; BMI, body mass index; WC, waist circumference; BBT, basal body temperature; SBP, systolic blood pressure; DBP, diastolic blood pressure; RHR, resting heart rate; FBG, fasting blood glucose; TG, triglyceride; TC, total cholesterol; LDL-C, low-density lipoprotein cholesterol; HDL-C, high-density lipoprotein cholesterol; Cr, creatinine; $\mathrm{CCr}$, creatinine clearance rate.



Figure 4. Association between UCP1 mRNA expression and Fuhrman grade. There was an increase in UCP1 mRNA expression with advancing Fuhrman grade. $r$ is the Spearman correlation coefficient and $\mathrm{P}<0.05$ indicates the significance level $(n=50)$. UCP1, uncoupling protein 1.

into two groups. No significant differences in sex, age, WC, BMI, BBT, RHR, histopathology, necrosis and metastasis were observed between the two groups (Table II). However, Fuhrman grade and T stage were higher in the high UCP1 expression group compared with those in the low UCP1 expression group.



Figure 5. Association between UCP1 mRNA expression and T stage. There was an increase in UCP1 mRNA expression with advancing T stage. $r$ is the Spearman correlation coefficient and $\mathrm{P}<0.05$ indicates the significance level $(\mathrm{n}=50)$. UCP1, uncoupling protein 1 .

\section{Discussion}

In the present study, PAT samples were divided into upper and lower renal pole samples. The results revealed no significant difference in UCP1 expression and adipocyte morphology, or the expression of other genes, between the two parts of the PAT. Letizia et al (27) reported that leptin expression in adrenal 
Table II. Comparison of baseline characteristics of RCC between the high and low expression UCP1 groups.

\begin{tabular}{|c|c|c|c|}
\hline Characteristics & Low UCP1 group $(n=29)$ & High UCP1 group $(n=21)$ & P-value \\
\hline Age (years) & $51.03 \pm 8.85$ & $53.76 \pm 7.42$ & 0.256 \\
\hline Male sex, n (\%) & $14(48.28)$ & $11(52.38)$ & 0.774 \\
\hline BMI $\left(\mathrm{kg} / \mathrm{m}^{2}\right)$ & $24.12 \pm 3.13$ & $24.56 \pm 2.67$ & 0.605 \\
\hline $\mathrm{WC}(\mathrm{cm})$ & $89.41 \pm 11.87$ & $91.00 \pm 10.10$ & 0.622 \\
\hline $\operatorname{BBT}\left({ }^{\circ} \mathrm{C}\right)$ & $36.53 \pm 0.26$ & $36.40 \pm 0.28$ & 0.084 \\
\hline RHR (bpm) & $74.21 \pm 7.45$ & $74.33 \pm 6.13$ & 0.949 \\
\hline Fuhrman grade, n (\%) & & & 0.020 \\
\hline I-II & $26(89.66)$ & $12(57.14)$ & \\
\hline III-IV & $3(10.34)$ & $9(42.86)$ & \\
\hline Histopathology, n (\%) clear cell RCC & $29(100.00)$ & $21(100.00)$ & 1.000 \\
\hline Necrosis, n (\%) & $10(34.48)$ & $6(28.57)$ & 0.658 \\
\hline T stage, $\mathrm{n}(\%)$ & & & 0.014 \\
\hline$\leq \mathrm{T} 2$ & $28(96.55)$ & $14(66.67)$ & \\
\hline$>\mathrm{T} 2$ & $1(3.45)$ & $7(33.33)$ & \\
\hline Metastasis, n (\%) & & & 1.000 \\
\hline N0 and M0 & $29(100.00)$ & $21(100.00)$ & \\
\hline N1-2 or M1 & $0(0.00)$ & $0(0.00)$ & \\
\hline
\end{tabular}

Data were analyzed by unpaired t-tests. All values are expressed as mean \pm standard deviation for continuous variables and as number of patients (percentage) for categorical variables. Continuous variables were analyzed by independent-sample t-tests, two-sided type I error of 0.05 . Categorical variables were analyzed by $\chi^{2}$-tests. RCC, renal cell carcinoma; UCP1, uncoupling protein 1; BMI, body mass index; WC, waist circumference; BBT, basal body temperature; RHR, resting heart rate.

fat was significantly higher, while adiponectin expression in adrenal neoplasia was significantly lower compared with that in subcutaneous tissues and PAT in patients with Cushing's syndrome. In the present study, patients with adrenal tumors were excluded, so it may be hypothesized that normal adrenal glands would not affect the properties of PAT.

Süer et al (14) reported that PAT invasion may predict the prognosis of RCC patients. Bedke et al (15) found that perinephric and renal sinus fat infiltration may indicate an unfavorable prognosis of RCC. However, the role of PAT in RCC remains unclear. The present results demonstrated that increased UCP1 expression in PAT was correlated with RCC. Furthermore, it was found that the Fuhrman grade and $\mathrm{T}$ stage were higher in the high UCP1 expression group compared with the low UCP1 expression group, while age, sex, BMI, WC, BBT, RHR, histopathology, necrosis and metastasis were not significantly different between the two groups. These results suggested that high UCP1 expression in PAT may serve as an indicator of poor prognosis.

Thermogenesis is a key property and function that leads to the browning of adipose tissue. There have been a number of studies demonstrating that an increase in UCP1 expression may be involved in cancer-associated cachexia (CAC) $(21,28,29)$. In the present study, when the subjects were divided into two groups by the median UCP1 expression in PAT, it was found that the number of patients with Fuhrman grade III-IV and $\mathrm{T}$ stage $>\mathrm{T} 2$ was markedly increased in the high UCP1 expression group, while BMI exhibited no significant difference between the two groups. Furthermore, a correlation test of UCP1 levels in patients with RCC was performed. The data demonstrated that the expression of UCP1 mRNA was significantly positively correlated with Fuhrman grade and T stage in RCC, whereas BMI exhibited no such correlations (Figs. S1 and S2). Following a literature search, Kir et al (30) reported that the browning effect of WAT could be observed during the early stages of CAC, prior to the total weight loss. Petruzzelli et al (31) also reported similar findings, and named the mice at this stage as 'precachectic'. It is known that RCC is a type of low-grade malignancy. The majority of RCC patients in the present study were within or even above the normal BMI range (BMI 19.37-28.98 $\mathrm{kg} / \mathrm{m}^{2}$ ), similar to precachetic animals. Only in 1 female patient the BMI was $16.48 \mathrm{~kg} / \mathrm{m}^{2}$, and her UCP1 mRNA expression in PAT was 1.745. Therefore, it was considered that, as a type of low-grade malignancy, RCC patients seldom reach a cachectic stage, but a marked browning of PAT may be observed from the very early stages.

Accumulating evidence has indicated that adipocytes stimulate cancer cell growth $(32,33)$. Adipocytes secrete adipocytokines to promote the homing of ovarian cancer cells and provide fuel for cancer cell growth (34). The induction of mitochondrial dysfunction via UCP expression in cancer-associated fibroblasts also promotes cancer growth, but the induction of mitochondrial dysfunction in epithelial cancer cells inhibits cancer growth by inducing catabolism (35). In the present study, no differences in the expression of adipocytokines and proinflammatory cytokines between the control and RCC groups were identified. However, it was observed that increased UCP1 expression was associated with low HOXC8 and HOXC9 expression in the PAT, which indicates that, with the diminished properties of WAT, the browning of the PAT in patients with RCC is increased. Whether increased UCP1 expression in the 
PAT could regulate the metabolism and growth of RCC cells by supporting energy production remains to be investigated.

In conclusion, UCP1 expression is similar between different parts of the PAT, and increased UCP1 expression in the PAT is correlated with the development of RCC and may be associated with a poor prognosis of patients with RCC.

\section{Acknowledgements}

Not applicable.

\section{Funding}

The present study was supported by the National Natural Science Foundation of China (grant nos. 81570773 and 81871106), and the Huai'an 2016 Annual Promotion Project for Science and Technology International Cooperation (grant nos. HAC201622 and HAC201620).

\section{Availability of materials and data}

All the datasets generated and analyzed in the present study are available from the corresponding author on reasonable request.

\section{Authors' contributions}

XL, GW, JL and GD designed this study. XL and GW collected and analyzed the data. XL and JL contributed materials. XL, JL and GW wrote the manuscript. All the authors have read and approved the final version of this manuscript for publication.

\section{Ethics approval and consent to participate}

All procedures involving human subjects followed the standards of and were approved by the Ethics Committee of Nanjing Medical University (no. 2013-SRFA-132). All subjects signed informed consent.

\section{Patient consent for publication}

Not applicable.

\section{Competing interests}

The authors declare that they have no competing interests.

\section{References}

1. Rini BI, Campbell SC and Escudier B: Renal cell carcinoma. Lancet 373: 1119-1132, 2009.

2. Motzer RJ, Bander NH and Nanus DM: Renal-cell carcinoma. N Engl J Med 335: 865-875, 1996.

3. Ferlay J, Shin HR, Bray F, Forman D, Mathers C and Parkin DM: Estimates of worldwide burden of cancer in 2008: GLOBOCAN 2008. Int J Cancer 127: 2893-2917, 2010.

4. Ljungberg B, Campbell SC, Choi HY, Jacqmin D, Lee JE, Weikert S and Kiemeney LA: The epidemiology of renal cell carcinoma. Eur Urol 60: 615-621, 2011.

5. Drabkin HA and Gemmill RM: Obesity, cholesterol, and clear-cell renal cell carcinoma (RCC). Adv Cancer Res 107: 39-56, 2010.

6. Samanic C, Chow WH, Gridley G, Jarvholm B and Fraumeni JF Jr: Relation of body mass index to cancer risk in 362,552 Swedish men. Cancer Causes Control 17: 901-909, 2006.
7. Adams KF, Leitzmann MF, Albanes D, Kipnis V, Moore SC Schatzkin A and Chow WH: Body size and renal cell cancer incidence in a large US cohort study. Am J Epidemiol 168: 268-277, 2008.

8. Liao LM, Weinstein SJ, Pollak M, Li Z, Virtamo J, Albanes D, Chow WH and Purdue MP: Prediagnostic circulating adipokine concentrations and risk of renal cell carcinoma in male smokers. Carcinogenesis 34: 109-112, 2013.

9. Spyridopoulos TN, Petridou ET, Dessypris N, Terzidis A Skalkidou A, Deliveliotis C, Chrousos GP and Obesity and Cancer Oncology Group: Inverse association of leptin levels with renal cell carcinoma: Results from a case-control study. Hormones (Athens) 8: 39-46, 2009.

10. Pinthus JH, Kleinmann N, Tisdale B, Chatterjee S, Lu JP, Gillis A, Hamlet T, Singh G, Farrokhyar F and Kapoor A: Lower plasma adiponectin levels are associated with larger tumor size and metastasis in clear-cell carcinoma of the kidney. Eur Urol 54: 866-873, 2008

11. Yoshida N, Ikemoto S, Narita K, Sugimura K, Wada S, Yasumoto R, Kishimoto T and Nakatani T: Interleukin-6, tumor necrosis factor alpha and interleukin-lbeta in patients with renal cell carcinoma. Br J Cancer 86: 1396-1400, 2002.

12. Ho MY, Tang SJ, Chuang MJ, Cha TL, Li JY, Sun GH and Sun KH: TNF- $\alpha$ induces epithelial-mesenchymal transition of renal cell carcinoma cells via a GSK3 $\beta$-dependent mechanism. Mol Cancer Res 10: 1109-1119, 2012.

13. Lamacchia O, Nicastro V, Camarchio D, Valente U, Grisorio R, Gesualdo L and Cignarelli M: Para- and perirenal fat thickness is an independent predictor of chronic kidney disease, increased renal resistance index and hyperuricaemia in type-2 diabetic patients. Nephrol Dial Transplant 26: 892-898, 2011.

14. Süer E, Baltaci S, Burgu B, Aydoğdu Ö and Göğüş Ç: Significance of tumor size in renal cell cancer with perinephric fat infiltration: Is TNM staging system adequate for predicting prognosis? Urol J 10: 774-779, 2013.

15. Bedke J, Buse S, Pritsch M, Macher-Goeppinger S, Schirmacher P, Haferkamp A and Hohenfellner M: Perinephric and renal sinus fat infiltration in pT3a renal cell carcinoma: Possible prognostic differences. BJU Int 103: 1349-1354, 2009.

16. Ricquier D: Respiration uncoupling and metabolism in the control of energy expenditure. Proc Nutr Soc 64: 47-52, 2005.

17. Cannon B and Nedergaard J: Brown adipose tissue: Function and physiological significance. Physiol Rev 84: 277-359, 2004.

18. Tam CS, Lecoultre V and Ravussin E: Brown adipose tissue mechanisms and potential therapeutic targets. Circulation 125: 2782-2791, 2012.

19. Kozak LP and Anunciado-Koza R: UCP1: Its involvement and utility in obesity. Int J Obes 32 (Suppl): S32-S38, 2008.

20. Rousseau C, Bourbouloux E, Campion L, Fleury N, Bridji B, Chatal JF, Resche I and Campone M: Brown fat in breast cancer patients: Analysis of serial (18)F-FDG PET/CT scans. Eur J Nucl Med Mol Imaging 33: 785-791, 2006.

21. Bianchi A, Bruce J, Cooper AL, Childs C, Kohli M, Morris ID, Morris-Jones $\mathrm{P}$ and Rothwell NJ: Increased brown adipose tissue activity in children with malignant disease. Horm Metab Res 21: 640-641, 1989

22. Li X, Liu J, Wang G, Yu J, Sheng Y, Wang C, Lv Y, Lv S, Qi H, Di W, et al: Determination of UCP1 expression in subcutaneous and perirenal adipose tissues of patients with hypertension. Endocrine 50: 413-423, 2015.

23. Yeatts K: Quantitative polymerase chain reaction using the comparative C q method. Methods Mol Biol 700: 171-184, 2011.

24. Cypess AM, Lehman S, Williams G, Tal I, Rodman D, Goldfine AB, Kuo FC, Palmer EL, Tseng YH, Doria A, et al: Identification and importance of brown adipose tissue in adult humans. N Engl J Med 360: 1509-1517, 2009.

25. Ouellet V, Routhier-Labadie A, Bellemare W, Lakhal-Chaieb L, Turcotte E, Carpentier AC and Richard D: Outdoor temperature, age, sex, body mass index, and diabetic status determine the prevalence, mass, and glucose-uptake activity of 18F-FDG-detected BAT in humans. J Clin Endocrinol Metab 96: 192-199, 2011.

26. Pfannenberg C, Werner MK, Ripkens S, Stef I, Deckert A, Schmadl M, Reimold M, Häring HU, Claussen CD and Stefan N: Impact of age on the relationship of brown adipose tissue with sex and adiposity in humans. Diabetes 59: 1789-1793, 2010.

27. Letizia C, Petramala L, Di Gioia CR, Chiappetta C, Zinnamosca L, Marinelli C, Iannucci G, Ciardi A, De Toma G and Iacobellis G: Leptin and adiponectin mRNA expression from the adipose tissue surrounding the adrenal neoplasia. J Clin Endocrinol Metab 100: E101-E104, 2015. 
28. Tsoli M, Moore M, Burg D, Painter A, Taylor R, Lockie SH, Turner N, Warren A, Cooney G, Oldfield B, et al: Activation of thermogenesis in brown adipose tissue and dysregulated lipid metabolism associated with cancer cachexia in mice. Cancer Res 72: 4372-4382, 2012.

29. Kir S, Komaba H, Garcia AP, Economopoulos KP, Liu W, Lanske B, Hodin RA and Spiegelman BM: PTH/PTHrP receptor mediates cachexia in model of kidney failure and cancer. Cell Metab 23: 315-323, 2016.

30. Kir S, White JP, Kleiner S, Kazak L, Cohen P, Baracos VE and Spiegelman BM: Tumor derived PTH-related protein triggers adipose tissue browning and cancer cachexia. Nature 523: 100-104, 2014

31. Petruzzelli M, Schweiger M, Schreiber R, Campos-Olivas R, Tsoli M, Allen J, Swarbrick M, Rose-John S, Rincon M, Robertson $\mathrm{G}$, et al: A switch from white to brown fat increases energyexpenditure in cancer-associated cachexia. Cell Metab 20: 433-447, 2014

32. Manabe Y, Toda S, Miyazaki K and Sugihara H: Mature adipocytes, but not preadipocytes, promote the growth of breast carcinoma cells in collagen gel matrix culture through cancer-stromal cell interactions. J Pathol 201: 221-228, 2003.
33. Dirat B, Bochet L, Dabek M, Daviaud D, Dauvillier S, Majed B, Wang YY, Meulle A, Salles B, Le Gonidec S, et al: Cancer-associated adipocytes exhibit an activated phenotype and contribute to breast cancer invasion. Cancer Res 71: 2455-2456, 2011.

34. Nieman KM, Kenny HA, Penicka CV, Ladanyi A, Buell-Gutbrod R, Zillhardt MR, Romero IL, Carey MS, Mills GB, Hotamisligil GS, et al: Adipocytes promote ovarian cancer metastasis and provide energy for rapid tumor growth. Nat Med 17: 1498-1503, 2011.

35. Sanchez-Alvarez R, Martinez-Outschoorn UE, Lamb R, Hulit J, Howell A, Gandara R, Sartini M, Rubin E, Lisanti MP and Sotgia F: Mitochondrial dysfunction in breast cancer cells prevents tumor growth: Understanding chemoprevention with metformin. Cell Cycle 12: 172-182, 2013.

This work is licensed under a Creative Commons Attribution-NonCommercial-NoDerivatives 4.0 International (CC BY-NC-ND 4.0) License. 